\title{
O Modelo Delta como opção de posicionamento estratégico para empresas de TI
}

\author{
Eduardo Almansa Sortica, Fernando Ceragioli \\ UNCENP \\ sortica@gmail.com, fernando.ceragioli@bol.com.br
}

\begin{abstract}
Resumo. O Modelo Delta de posicionamento estratégico apresenta 3 núcleos básicos de opções estratégicas que podem ser aplicados na gestão de organizações de TI, são eles: system lock-in, melhor produto e solução para o cliente. Através da aplicação destas estratégias foi feita uma análise com base na categoria e segmento de serviços de TI definidos em IDG Brasil (2006) e foi concluído que as organizações estudadas encontram-se entre as posições estratégicas de melhor produto e solução para o cliente. Em contrapartida, a estratégia de system lock-in, que se caracteriza por dependência tecnológica, não foi comumente encontrada dentro do universo dos segmentos avaliados.
\end{abstract}

\section{Introdução aos modelos de estratégia e processos}

Nesse contexto são consideradas três perspectivas básicas do plano estratégico formal de uma empresa: a estratégica corporativa, a estratégica do negócio e a estratégia funcional. Em Mintzberg (1996), a estratégia corporativa trata as decisões que abrangem toda a empresa. A estratégia do negócio tem por objetivo viabilizar o negócio do ponto de vista financeiro de modo que a empresa se posicione à frente de seus competidores. A estratégia funcional não somente consolida os requisitos funcionais demandados pelas estratégias da corporação e do negócio, mas também constitui um depositório das capacidades necessárias para o desenvolvimento da competência da empresa.

Nesse estudo, foram vistos dois modelos complementares para definição da estratégia de uma empresa: o Modelo Delta que trata da análise do posicionamento estratégico da empresa no momento presente e direcionamento para um novo modelo; o Modelo das 5 forças de Porter, definido em Porter (1980), que trata da análise competitiva da empresa associada e estabelecimento de uma estratégia de mudança para direcionamento para um novo modelo.

\section{Referencial Teórico}

\subsection{As 5 Forças de Porter}

O Modelo das 5 Forças (figura 1) trata de aspectos da estratégia competitiva, que tem como objetivo para uma dada empresa estabelecer forças competitivas próprias e influenciá-las a seu favor. As 5 forças que dirigem a competição na indústria são: Entrantes Potenciais (novas empresas que podem entrar no mercado), Compradores 
(poder de compra e negociação dos compradores), Fornecedores (poder de influencia e negociação dos fornecedores), Substitutos (novos produtos ou serviços que podem substituir os existentes), Concorrência na Indústria (competição entre as empresas existentes no mercado). A análise estrutural da influência e como pode ser utilizada cada uma das forças é a base fundamental da formulação da estratégia competitiva.

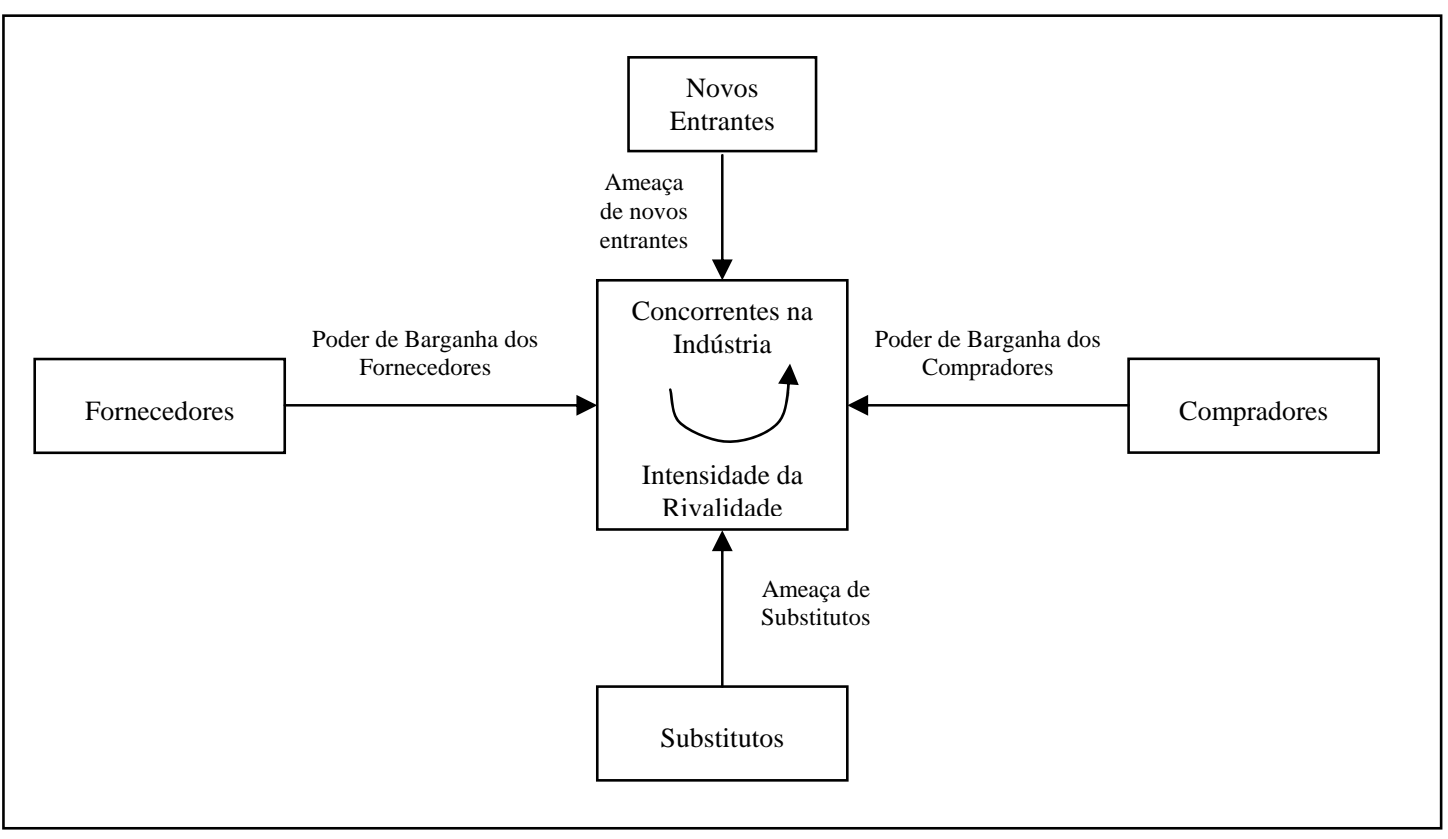

Figura 1 - As 5 forças de Porter

\subsection{O modelo delta: visão geral}

O Modelo Delta trata de aspectos da estratégia oriundos da análise prática de empresas que obtiveram sucesso em cada uma das opções estratégicas conceituadas por este modelo. Dentre as contribuições principais do Modelo Delta para o pensamento estratégico, é importante responder a duas questões: Qual é o propósito central da estratégia? Quais são os meios de atingi-lo? As respostas para estas questões estão nos 3 dogmas da estratégia, segundo Hax (1996), que definem como uma empresa deve se comportar de modo a atingir o sucesso no mercado, independente da opção estratégica adotada. Os três definem o propósito da estratégia e as maneiras de como atingir este objetivo. O primeiro dogma é “A Criação de Valor Econômico”: Atingir desempenho superior e sustentável medido em lucratividade de longo prazo. O segundo dogma é "A Criação da Proposição de Cliente de Valor Único”: É a satisfação do cliente suportada pela proposição de valor único. Significa basicamente atrair, satisfazer e reter o cliente. O terceiro dogma é “A Criação do Espírito do Sucesso": O Fluxo de talentos e networking. Significa atrair, satisfazer e reter os empregados superiores (talentos) para manter e obter vantagens competitivas no mercado.

O modelo delta, baseado nos seus conceitos, oferece 4 contribuições relacionadas à estratégia empresarial. Se considerarmos estes princípios como um todo, o modelo constitui um novo método de estratégia empresarial e uma nova disciplina de estratégia gerencial. As quatro contribuições deste modelo, como mostradas no quadro 1, são as seguintes: o triângulo (delta), os processos adaptativos, as métricas, a experimentação e o feedback. 
Quadro 1 - As contribuições do modelo Delta

\begin{tabular}{|c|c|c|c|}
\hline \multicolumn{4}{|c|}{ CONTRIBUIÇÕES DO MODELO DELTA } \\
\hline & Objetivos & Implicações & Método \\
\hline 을 & $\begin{array}{l}\text { Abrindo a cabeça para } \\
\text { as novas posições da } \\
\text { estratégia }\end{array}$ & $\begin{array}{l}\text { O melhor produto } \\
\text { nem sempre vence }\end{array}$ & $\begin{array}{l}\text { As } 3 \text { opções da estratégia: } \\
\text { • melhor produto } \\
\text { • solução total para o cliente } \\
\text { • system lock-in }\end{array}$ \\
\hline 总 & $\begin{array}{l}\text { Como ligar estratégia } \\
\text { com execução }\end{array}$ & $\begin{array}{l}\text { Execução não é o } \\
\text { problema principal, } \\
\text { ligar execução e } \\
\text { estratégia sim }\end{array}$ & $\begin{array}{l}\text { Execução realizada através } \\
\text { de } 3 \text { processos adaptativos: } \\
\text { • eficácia operacional } \\
\text { • foco no cliente } \\
\text { • inovação } \\
\end{array}$ \\
\hline 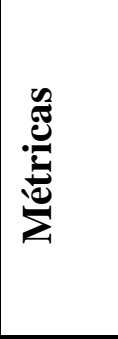 & $\begin{array}{l}\text { Agregar métricas não é } \\
\text { o suficiente, é preciso } \\
\text { complementar métricas } \\
\text { de negócio com } \\
\text { métricas de serviços }\end{array}$ & $\begin{array}{l}\text { Gerenciamento por } \\
\text { média leva a } \\
\text { desempenho abaixo } \\
\text { da média }\end{array}$ & $\begin{array}{l}\text { As métricas de desempenho } \\
\text { são alinhadas com opções de } \\
\text { estratégia e processos. } \\
\text { As métricas de serviços são } \\
\text { associadas aos processos } \\
\text { produtivos, de distribuição, } \\
\text { venda, etc. }\end{array}$ \\
\hline بَّ & $\begin{array}{l}\text { Uso de experimentação } \\
\text { e feedback como } \\
\text { mecanismos adaptativos }\end{array}$ & $\begin{array}{l}\text { Planos não foram } \\
\text { feitos para } \\
\text { seguidos }\end{array}$ & $\begin{array}{l}\text { Uma grande transformação } \\
\text { empresarial somente é } \\
\text { atingida através de } \\
\text { experimentação cuidadosa, } \\
\text { aprendizado } \\
\text { implementação. Mecanismos } \\
\text { de feedback são importantes } \\
\text { para adaptação de processos } \\
\text { e gerência de mudanças }\end{array}$ \\
\hline
\end{tabular}

\subsection{O Triângulo: Novas Opções de Estratégia}

A primeira reflexão que a normalmente toma parte no processo de definição da estratégia de uma empresa ou de um negócio é justamente decidir o quão é relevante a posição estratégica desta empresa. Isto é simplesmente uma tentativa de capturar a essência e como a empresa compete no seu nicho de mercado principal ou, em outras palavras, como a empresa decide atrair, satisfazer e reter os seus clientes.

Conceitualmente são reconhecidas três opções distintas de estratégias, segundo Hax e Wilde (2001), todas oferecem maneiras diferentes de alcançado no relacionamento definitivo com créditos. Graficamente estas três opções são mostradas como um triângulo. Essa figura geométrica foi escolhida por apresentar estas diferentes visões, como ícone é fácil de ser lembrada, mas também por representar a letra delta que significa a transformação.

As estratégias relacionadas ao triângulo são apresentadas no quadro 2. 
Quadro 2 - Características das 3 opções de posicionamento estratégico

\begin{tabular}{|c|c|c|c|}
\hline \multicolumn{4}{|c|}{ Características das 3 opções de posicionamento estratégico } \\
\hline & Melhor Produto & Soluções para o Cliente & Lock-In do Sistema \\
\hline$\frac{\mathscr{J}}{2}$ & $\begin{array}{l}\text { Descaracterizado: } \\
\text { - Baixo custo } \\
\text { Cheio de qualidades: } \\
\text { - } \quad \text { Diferenciado }\end{array}$ & $\begin{array}{l}\text { Ampla gama de produtos: } \\
\text { - Pacotes } \\
\text { - Desenvolvimento conjunto } \\
\text { - Terceirização }\end{array}$ & $\begin{array}{l}\text { Estimular os } \\
\text { complementares: } \\
\text { - Variedade e número } \\
\text { - Arquitetura aberta }\end{array}$ \\
\hline 苞 & $\begin{array}{l}\text { Produto: } \\
\text { - } \quad \text { Participação no } \\
\text { mercado }\end{array}$ & $\begin{array}{l}\text { Cliente: } \\
\text { • } \quad \text { Participação do cliente }\end{array}$ & $\begin{array}{l}\text { Sistema: } \\
\text { - } \quad \text { Participação do } \\
\quad \text { complementar }\end{array}$ \\
\hline 总 & $\begin{array}{l}\text { Conexão com o produto: } \\
\text {-O primeiro no mercado } \\
\text { •Projeto dominante }\end{array}$ & $\begin{array}{l}\text { Conexão com os clientes: } \\
\text { - "Captação" do cliente } \\
\text { - Aprendizado } \\
\text { - } \quad \text { Personalização }\end{array}$ & $\begin{array}{l}\text { Conexão com o } \\
\text { sistema: } \\
\text { - } \quad \text { Afastamento do } \\
\text { concorrente } \\
\text { - } \quad \text { Padrões próprios }\end{array}$ \\
\hline
\end{tabular}

\section{Aspectos Metodológicos}

A classificação das empresas eleitas Destaque no Ranking geral das 100 maiores de TI e Telecom 2006, do IDG, tomou como parâmetro único o valor da movimentação pela companhia dentro do mercado de TI (hardware, software e infra-estrutura) e Telecom (equipamentos, soluções e serviços de telecom) e de canais de distribuição. O estudo feito pela Meka, empresa especializada em consultoria na área de TI e telecom, utilizou as seguintes informações:

- As empresas foram classificadas num primeiro momento em função do valor faturado dentro de cada categoria, de onde saíram os 10 maiores (quando aplicável);

- Dentro das 10 maiores empresas, elegeu-se o destaque (que deveria possuir mais de $5 \%$ de share na respectiva categoria) levando em consideração os seguintes quesitos com os respectivos pesos: crescimento do faturamento em reais (60\%), market share (35\%), peso do segmento em relação às receitas de TI e Telecom (5\%).

A Meka utilizou as seguintes ferramentas para coletar as informações e classificar as empresas: malas direta por e-mail - base interna disponível agregando empresas fornecidas pela IDG, além de complementar com a base de empresas da Abinee (Associação Brasileira de Indústrias Eletro e Eletrônica), formando um banco de contatos com 738 executivos, além das assessorias de imprensa. Algumas empresas não forneceram números e a Meka estimou dados de 81 companhias. Para valores que foram convertidos para o real, foram utilizadas as seguintes taxas de conversão: dólar médio: 2003 - R\$ 3,11; $2004-\mathrm{R} \$ 2,92$ e 2005 - R\$ 2,43.

\section{Estudo de Caso: A Classificação segundo o Triângulo Delta}

Neste estudo de caso foi realizada uma análise das categorias e segmentos dos serviços de TI conforme definidos em IDG Brasil (2006), sob a ótica do modelo estratégico de Hax e Wilde II (2001). As categorias e segmentos são classificados da seguinte forma: 
- $\quad$ TI - Hardware: automação bancária; impressoras, scanners e multifuncionais; monitore; PCs, notebooks, handhelds; servidores.

- $\quad$ TI - Infra-estrutura: armazenamento, sistema de energia, redes corporativas.

- $\quad$ TI - Software: banco de dados, gerenciamento, gestão, segurança.

- Telecom: soluções de call center, celulares, comutação privada, telefonia IP, comutação pública, consultoria e integração, plataforma de mobilidade, redes convergentes, terceirização, dados corporativos e residenciais, voz celular e fixa, canais de vendas (equipamentos de telecom).

- Canal de Distribuição: hardware e software.

O resultado da análise das categorias e seus respectivos segmentos a luz das estratégias do modelo delta são apresentadas de forma posicional na figura 2 .

\subsection{Melhor Produto}

A primeira estratégia chamada de melhor produto é a forma clássica de enfrentar a concorrência. Neste caso o consumidor é atrair do pelas características inerentes do produto, por exemplo, baixo custo, ou através de um diferencial, que introduz fatores únicos para os valores do cliente e que este está disposto a pagar o prêmio (adicional do valor do produto). A tendência natural é que estes produtos sejam padronizados e vendidos como pacotes. Em contrapartida o consumidor é genérico, de massa e impessoal. O foco central da atenção é a concorrência, que vamos superar o no mínimo mantermos no mesmo nível. Os meios para isto são os produtos e a cadeia de fornecimento, que fornece a máquina para a produção de produtos eficazes. A inovação tecnológica ou deve ser o centro do processo de desenvolvimento de produto interno.

Desse modo, com base nas características já apresentadas, nas categorias de TI Hardware e Canal de Distribuição, seus segmentos apresentam $80 \%$ ou mais de pontuação referente a opção estratégica de melhor produto. Também foi verificada uma tendência na categoria de Telecom, onde 10 dos 12 segmentos apresentam este tipo de estratégia.

\subsection{Solução para o Cliente}

O modo de estratégia chamado de solução total para o cliente é o inverso da abordagem de melhor produto. Ao invés de padronizar o produto ou serviço de maneira que o cliente fique na dependência deste, a organização procura um entendimento das necessidades do cliente e um nível de relacionamento que permita desenvolver valores individuais para cada cliente.

Com base nas características já apresentadas, nas categorias de TI - Software e Telecom, seus segmentos apresentam $80 \%$ ou mais de pontuação referente à opção estratégica de solução para o cliente. Foi verificada uma pontuação de $50 \%$ para melhor produto e $50 \%$ para solução para o cliente na categoria de TI - Infra-estrutura nos segmentos armazenamento, sistemas de energia e redes corporativas. 


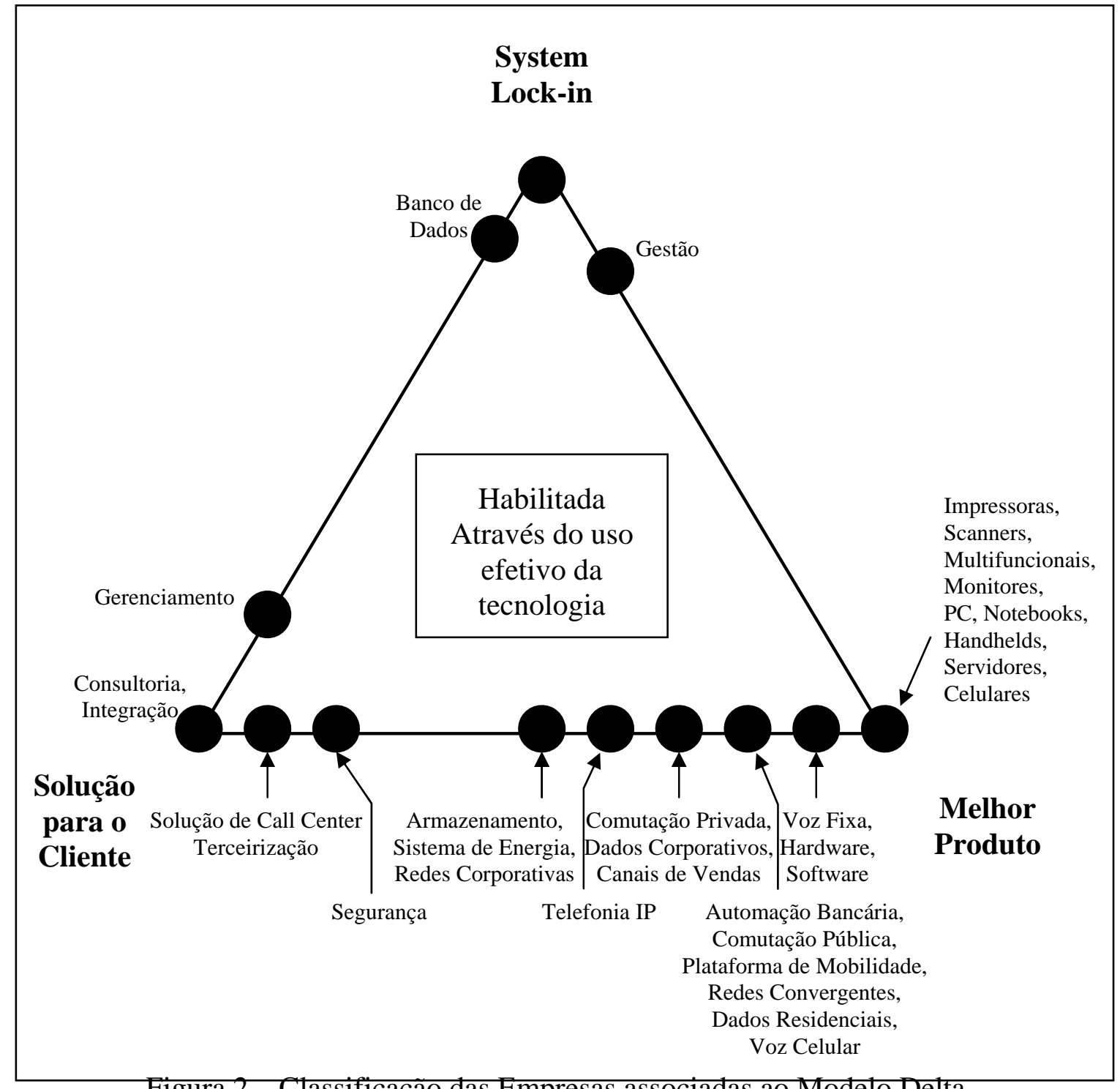

Figura 2 - Classificação das Empresas associadas ao Modelo Delta

\subsection{System Lock-in}

Este modo de estratégia tem escopo mais abrangente, incluindo as outras organizações, a firma, os clientes, os fornecedores, e o mais importante, as empresas complementares: os terceirizados. Uma empresa terceirizada é uma firma engajada na entrega de produtos e serviços que permite tornar estes como parte do portfólio da empresa. O ponto chave desta estratégia é identificar, atrair, e alavancar estes terceiros. Os terceirizados são geralmente externos, mas em alguns casos podem ser um departamento interno de uma empresa ou outra unidade de negócio, particularmente em grandes corporações. Os serviços terceirizados raramente são eficazmente e explorados por uma organização.

Com base nas características já apresentadas, apenas na categoria de TI - Software e nos segmentos de banco de dados e gestão pode-se verificar $80 \%$ ou mais de pontuação referente à opção estratégica de system lock-in. 


\section{Considerações finais}

O modelo Delta como opção de posicionamento estratégico de organizações de TI, pode trazer um conjunto de benefícios técnicos e operacionais à organização usuária e no inter-relacionamento com a organização de TI. As prerrogativas do foco dos serviços de TI e o modo de atendimento às organizações usuárias em suas categorias e segmentos de atuação, podem ser pontuadas e posicionadas no triângulo da estratégia como uma maneira de institucionalizar o padrão de atuação. Por sua vez, dentro do escopo das opções estratégicas do modelo Delta - melhor produto, solução para o cliente e system lock-in - permite, entre outros aspectos relacionados às categorias de serviços de TI, mensurar e posicionar os segmentos e desta forma enquadrar empresas atuantes no mercado nacional dentro do escopo de cada estratégia.

Entre as vantagens da aplicação do modelo Delta neste estudo pode-se identificar: melhor visualização da segmentação dos serviços e motivação das organizações de TI para determinado posicionamento estratégico. Para Fine (1983) aumento da competitividade e produtividade através da identificação dos competidores por categoria/segmento e formas de atuação, justificativa dos custos de tecnologia, e fornecimento de serviços alinhados ao negócio da organização.

As estratégias de solução para o cliente e melhor produto são amplamente utilizadas. A receita total das categorias de TI e Telecom indicadas pela IDG Brasil (2006) somam R \$ 157,9 bilhões (equivalente a US\$ 65 bilhões) sendo que as opções estratégicas de solução para o cliente e melhor produto somam 99\% desta quantia. Apenas 1\% desta receita esta relacionada a categoria com opção estratégica de system lock-in.

Um novo estudo pode ser sugerido para verificar se as estratégias que levaram as organizações de TI e Telecom, preferencialmente a solução para o cliente e melhor produto, foram implementadas a partir do conhecimento deste modelo através de estratégias deliberadas ou emergentes. Um segundo aspecto é que na falta do conhecimento deste modelo pelas organizações de TI e Telecom poderia ser analisado o porquê destes posicionamentos. Por último, pode ser estudado se a opção de posicionamento estratégico de system lock-in não foi escolhida por falta de conhecimento ou por ser de difícil implementação.

\section{Referências}

CLEMENTI, Sérgio; SORTICA, Eduardo Almansa; CARVALHO, Tereza Cristina M. B. Governança de TI: uma empresa virtual analisada sob a ótica do COBIT e do ITIL. EPUSP/LARC, São Paulo (SP), 2004.

FINE, C. H.. Quality control and learning in productive systems. Unpublished doctoral dissertation, Stanford University, Graduate School of Business, 1983.

HAX, Arnold; MAJLUF, N.S. The Strategy Concept and Process - A Pragmatic Approach. Prentice hall: New Jersey, 1996.

HAX, Arnold; WILDE II, Dean L. The delta project: discovering new sources of profitability in networked economy. Palgrave: New york, 2001.

IDG Brasil. 100 Maiores TI \& Telecom. Computerworld: São Paulo, 2006. 
MINTZBERG, H., \& QUINN, J. B. The strategy process: concepts, contexts, cases. New Jersey: Prentice Hall, 1996.

PORTER, Michael. Estratégia Competitiva - Técnicas para Análise de Indústrias e da Concorrência. Editora Campus: Rio de Janeiro, 1980. 